\title{
DIFERENTES PERSPECTIVAS DA AÇÃO DE MEMBROS INFERIORES NOS QUATRO NADOS COMPETITIVOS: UMA REVISÃO INTEGRATIVA
}

\section{Different perspectives of the action of lower members in the four competitive names: an integrative review}

\section{Marcelo de Oliveira Pinto@* Milena Julia Chirolli†@@Helio Roesler@‡ Suzana Matheus Pereira@§}

\footnotetext{
Doutor em Ciência do Movimento Humano e Mestre em Ciência do Movimento Humano pela Universidade do Estado de Santa Catarina; Professor na Universidade do Oeste de Santa Catarina.

t Graduanda no Curso de Fisioterapia da Universidade do Estado de Santa Catarina.

‡ Doutor em Engenharia Mecânica e Mestre em Engenharia Civil pela Universidade Federal do Rio Grande do Sul; Professor da Universidade do Estado de Santa Catarina.

§ Doutora em Ciências do Desporto pela Universidade do Porto, Portugal; Mestra em Ciências do Movimento Humano pela Universidade do Estado de Santa Catarina; Professora da Universidade do Estado de Santa Catarina
}

Resumo: $\quad$ Atualmente se sabe que a velocidade da natação é uma função da propulsão gerada a partir dos membros inferiores e não apenas dos membros superiores. No entanto, por anos, a ação das pernas, durante o nado, teve sua importância mitigada. Dessa forma, o objetivo deste trabalho foi levantar, por meio de uma revisão integrativa da literatura, o estado da arte acerca da importância dos membros inferiores na natação. Esta pesquisa foi delimitada na ação das pernas de superfície e pernas subaquáticas, excluindo-se as análises das saídas e viradas. Foram analisados estudos indexados nas seguintes bases de dados: Web of Science, PubMed, Scopus, Lilacs e SciELO. A sistematização de busca incluiu leitura de títulos, resumos e artigos na íntegra, encontrados por meio de blocos de descritores que combinaram termos principais e secundários. Um total de 154 artigos foi encontrado, dos quais 55 foram incluídos para análise qualitativa. Os resultados mostraram que os estudos sobre a utilização dos membros inferiores na natação possuem baixo valor amostral e descrição heterogênea dos níveis dos participantes. O nado peito e as ondulações subaquáticas são as variáveis mais estudadas. Preconiza-se examinar a eficácia de outras variáveis antropométricas, cinemáticas e de coordenação para entender melhor a produção da velocidade máxima e considerar a importância de técnicas individuais na ação das pernas na natação. Ainda, no campo da utilização dos membros inferiores na natação, existem algumas lacunas, as quais os próprios artigos apontam. Essas demandas ficam por conta da força gerada por esses segmentos, além da discussão da importância em se considerarem fatores individuais na ação das pernas para os nadadores.

Palavras-chave: Força. Fisiologia. Antropometria. Biomecânica. Dinamometria. 


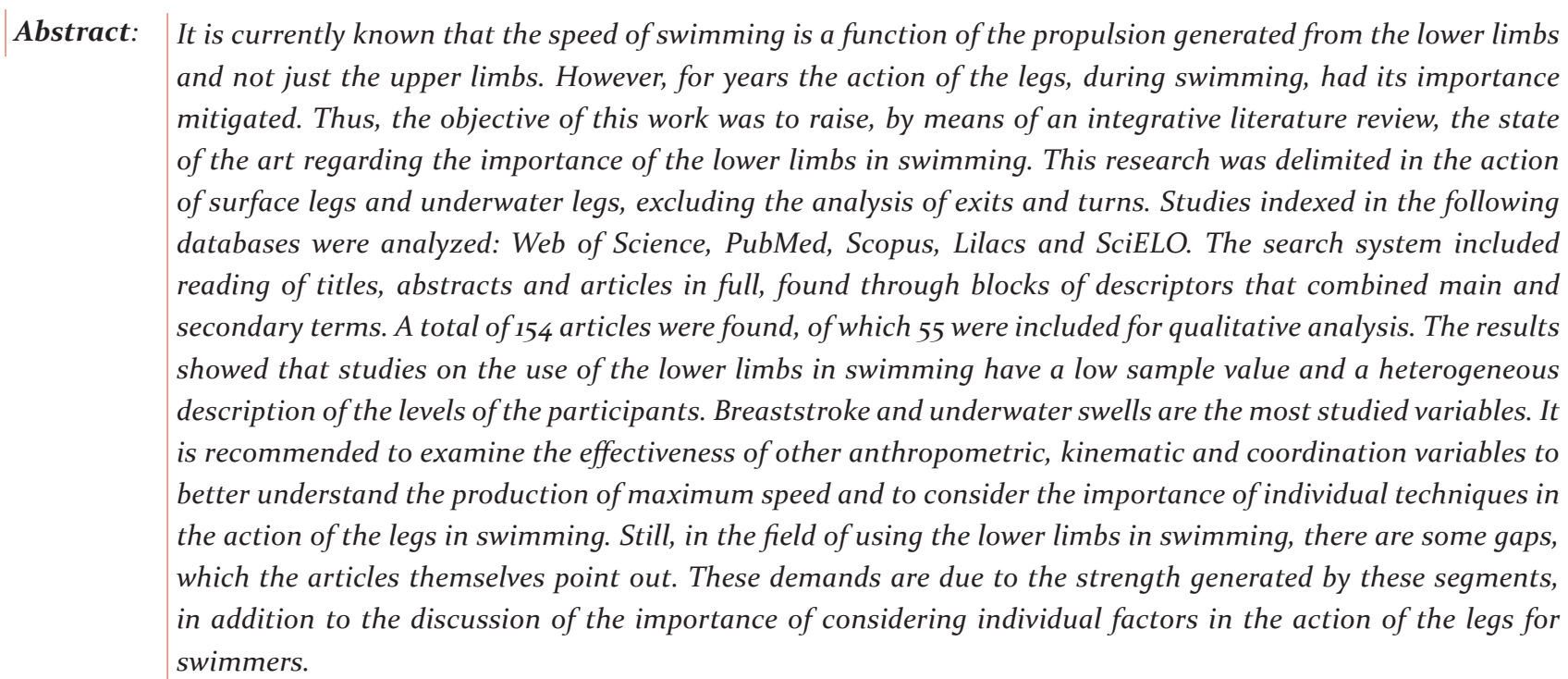
Keywords: Strength. Physiology. Anthropometry. Biomechanics. Dynamometry.

\section{INTRODUÇÃO}

Colocar um braço na frente do outro e repetir a sequência continua sendo a representação mais sólida do "caminho certo" para nadar. ${ }^{1}$ Entretanto, essa visão torna-se ultrapassada quando se almeja uma melhora significativa do desempenho na natação. A visão de que as pernas são, prioritariamente, um elemento equilibrador foi desconstruída no tempo. ${ }^{2}$ Por anos, as pernas, durante o nado (submerso ou não), tiveram sua importância mitigada. ${ }^{3}$ Mesmo entre os nadadores, a "pernada" era considerada um tabu. Para eles, a "pernada” na natação (mesmo a subaquática), era menos atraente, menos poderosa e menos rápida que colocar um braço na frente do outro. ${ }^{1}$ Apenas no nado peito as pernas eram compreendidas como fundamentais para o desempenho. ${ }^{4} \mathrm{O}$ estudo de Deschodt, Arsac e Rouard5 acabou por mitigar ainda mais a importância das pernas na natação, dado que, em sua pesquisa, foi quantificado que a contribuição relativa das pernas em humanos para propulsão em natação era de até 10\%.
Esses equívocos também se devem pela dificuldade em se realizar pesquisas no ambiente aquático. ${ }^{6} \mathrm{~A}$ ação das pernas é parcialmente obscurecida debaixo d`água, dificultando a análise da sua cinemática. 7 Sabe-se que a velocidade da natação é uma função da propulsão gerada a partir da ação dos braços e pernas, ${ }^{8}$ e, portanto, dependente da precisão da cinemática. Além disso, para esportes em que o ambiente influencia diretamente a cinemática, a exemplo da natação, a coleta de dados pode ser contaminada pelas condições que o ambiente proporciona. Assim, o uso de sistemas ópticos típicos é desafiador. ${ }^{9}$

Essa condição vem se modificando com o tempo. Os estudos apenas com células de carga e nados atados ${ }^{10}$ já estão ultrapassados. A inovação chegou para auxiliar no entendimento das variáveis de análise, que envolvem a melhora do desempenho, para compreender melhor a ação das pernas na natação. ${ }^{11-13}$ Novos estudos vêm surgindo na busca da melhor compreensão dos fatores associados à melhora no desempenho. Esses estudos buscam melhor entendimento sobre diversos aspectos, como a mobilidade articular ${ }^{14,15}$ 
e força dos membros inferiores - (MMII) na natação, ${ }^{16}$ e a utilização de novas tecnologias, como a dinâmica de fluidos computacional (CFD), ${ }^{12,17}$ além de sensores de detecção simultânea do movimento. ${ }^{18,19}$ Outra técnica de análise que vem ganhando campo é a utilização da eletromiografia de superfície. ${ }^{20-22}$ Não obstante, menos tradicionais são as análises que contam com cálculos das forças que afetam o nadador. ${ }^{12,23}$ Porém, a base das avaliações dos membros inferiores continua sendo as avaliações por cinemática, as quais retiram das imagens as conclusões esperadas. ${ }^{15,24-27}$ Nesse sentido, ao controlar parâmetros cinemáticos específicos e observar a resposta do nadador, pode-se entender que a cinemática é capaz de quantificar e ajudar na compreensão das variáveis que se pretende investigar.

Foi há 10 anos que o panorama da utilização dos membros inferiores na natação sofreu avanços. O estudo de Collard e Oboeuf ${ }^{1}$ physical education students should be capable of judging the true value of the I"fifth stroke, I" since it appears to be the most efficient technique in high level, competitive swimming. To compare opinions and connotations associated with the stroke and the four official strokes (butterfly, backstroke, breaststroke, and crawltrouxe a ondulação subaquática como o "quinto nado", justificando esse título pela expressão positiva que a ação das pernas gera para o nadador. A partir desse momento, autores como Fulton, Pyne e Burkett ${ }^{28}$ buscaram quantificar a ação dos membros inferiores na natação, compreendendo que esse movimento é um componente essencial para o nadador.

Sabendo que a velocidade na natação é determinada por fatores biomecânicos e bioenergéticos, ${ }^{29}$ com o avanço nas pesquisas, pode-se apontar que o movimento das pernas desempenha um papel importante na natação. ${ }^{8}$ Assim, os membros inferiores têm um alto potencial de reduzir tempos na natação, tornando o nadador mais competitivo. ${ }^{30}$ Zamparo, Vicentini, Scattolini, Rigamonti e Bonifazi ${ }^{31}$ indicam que nos primeiros 5 a 15 metros após a virada, a velocidade é essencialmente sustentada por uma hidrodinâmica adequada e também reflete a importância de uma boa execução do movimento ondulatório subaquático.

O que não foi compreendido ainda por muitos técnicos e pesquisadores é a ação dos membros inferiores na natação, que pode ser tão efetiva a ponto deobrigara Federação Internacional de Natação (Fina) a limitar a distância de 15 metros (exceto para o nado Peito), mesmo para provas de nado Livre, nas quais existe a crença de que os membros inferiores são pouco efetivos. ${ }^{1}$ Dessa forma, esta revisão integrativa tem por objetivo identificar a importância dos membros inferiores na natação. Esta pesquisa foi delimitada na ação das pernas de superfície e subaquática, excluindose as análises das saídas e viradas.

\section{MATERIAL E MÉTODOS}

\subsection{TIPO DE PESQUISA}

Neste estudo foi utilizada a metodologia da revisão integrativa, que consiste em levantar dados na finalidade de sintetizar resultados de pesquisas sobre um tema em questão. ${ }^{32} \mathrm{~A}$ busca ocorreu de forma sistemática, acerca dos membros inferiores e sua utilização na natação, nas principais bases de pesquisa científica.

Além disso, é de cunho bibliográfico, uma vez que se fundamenta na elaboração a partir de dados já publicados, como artigos de periódicos 
e demais materiais. ${ }^{33}$ Este trabalho também pode ser caracterizado como uma pesquisa qualitativa, ${ }^{34}$ que se deve pela qualificação dos estudos achados nas buscas.

\subsection{SELEÇÃO}

Foram analisados artigos presentes nas seguintes bases de dados: Web of Science, Scopus, SciELO, Medline, PubMed e Lilacs. Cada uma contou com estratégias de pesquisa individualizada. Os descritores e palavras-chave inseridos nas plataformas consistiram em três blocos. Para composição de cada bloco individual, o descritor principal e seus respectivos termos secundários foram combinados entre si pela utilização do booleano "OR", enquanto para a associação dos blocos se utilizou o booleano "AND".

A configuração utilizada para busca nas plataformas foi a seguinte: "((swimming) AND (Lower Extremity OR lower limb)) AND ((()((Biomechanical Phenomena) OR Biomechanic Phenomena) OR Mechanobiological Phenomena) OR Biomechanic Phenomenas) OR Kinematics))." Esses descritores também foram buscados em Português, Francês e Espanhol, para uma maior abrangência na busca dos estudos.

\subsubsection{Critérios de inclusão}

Somente periódicos indexados foram incluídos nessa busca, a fim de garantir o critério de qualidade para a produção. Os estudos selecionados deveriam atender aos seguintes critérios: estar em periódicos indexados; conter desenho experimental com humanos; apresentar dados que tivessem os membros inferiores na natação como variável de análise; englobar análises com estudos na área de Biomecânica.

\subsubsection{Critérios de exclusão}

Os artigos que não se enquadravam nos critérios de inclusão citados foram excluídos do estudo. Também foram excluídas pesquisas envolvendo: estudos com outros esportes aquáticos; estudos com saídas na natação; estudos com viradas na natação; estudos que não tivessem relação com os membros inferiores durante o nado ou que não permitissem avaliações a serem extrapoladas para a ação das pernas durante o nado.

\subsection{COLETA DE DADOS}

O primeiro autor coletou as informações necessárias para a seleção dos artigos. $\mathrm{O}$ segundo autor averiguou todas as informações coletadas para confirmar a precisão. Qualquer desacordo em qualquer fase foi resolvido por reunião e acordo mútuo entre os revisores.

O terceiro e o quarto autores estavam envolvidos na decisão final e na elaboração do manuscrito.

\subsection{PROCEDIMENTOS}

As estratégias de pesquisa serão descritas a seguir. O levantamento de dados iniciou em 20 de setembro de 2019 e a data final da pesquisa foi em 30 de setembro de 2019, sendo atualizada e concluída em 10 de julho de 2020.

A sistematização de busca incluiu uma hierarquia de avaliação com a busca dos artigos. Todas as referências foram gerenciadas pelo software gerenciador de referência EndNote ${ }^{\circ} \mathrm{X}_{3}$. Assim, todos os duplicados foram removidos nesse programa. Os estudos foram, primeiramente, avaliados pela leitura de títulos, seguida pela 
leitura dos resumos, e, por último, pela leitura dos artigos na íntegra, realizando a inclusão ou exclusão de artigos em cada etapa. Os estudos que não cumpriram os critérios de inclusão foram descartados. A avaliação está descrita na Figura 1.

Ao final das exclusões, os artigos completos ficaram para avaliação de conteúdo. A lista de referência de todos os artigos incluídos foi avaliada criticamente por um examinador. Um quarto autor, com vasta experiência em natação e atividades aquáticas, acompanhou a seleção e análise dos artigos e opinava sobre decisões quando havia controvérsias em uma decisão final. Tanto a seleção dos artigos quanto a leitura, correções e elaboração do manuscrito contaram com a participação dos quatro avaliadores/autores da obra.

\section{RESULTADOS}

A forma de seleção dos estudos é apresentada pelo Fluxograma da Figura 1, a seguir. Nele está descrito e identificado como ocorreu o processo de inclusão e exclusão dos estudos no decorrer das fases.

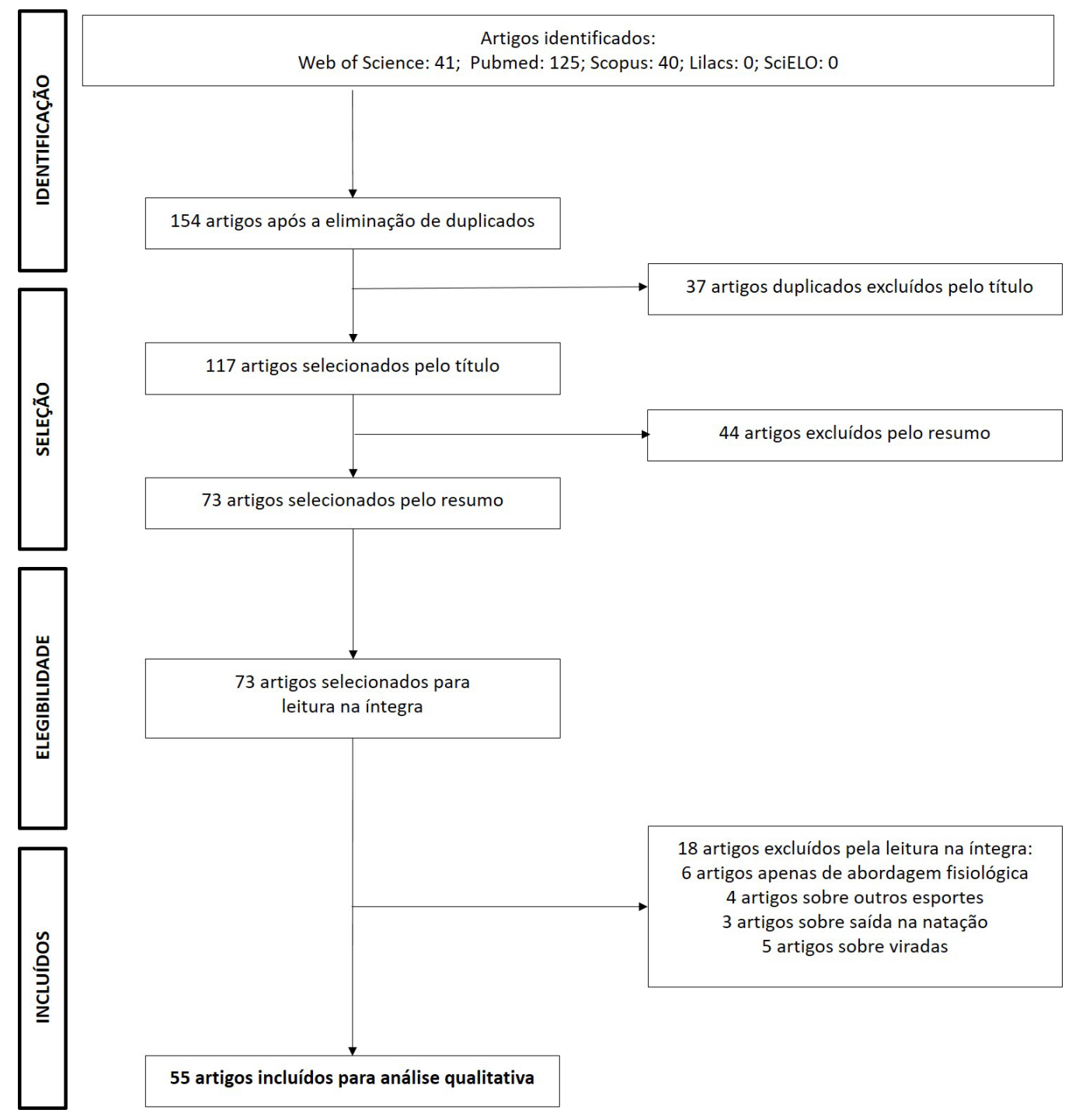

Figura 1 - Fluxograma da sistematização e critérios de busca, adaptados dos itens de relatório preferidos para revisões sistemáticas e metanálises (PRISMA). 
Na sequência, apresenta-se a Tabela 1, cada obra, participantes, respectivos temas e suas que contém informações acerca dos autores de conclusões gerais.

Tabela 1 - Apresentação dos artigos escolhidos para as análises qualitativas.

\begin{tabular}{|c|c|c|c|c|}
\hline & $\begin{array}{l}\text { Sujeitos da } \\
\text { pesquisa }\end{array}$ & Tema da pesquisa & Instrumentos & Principais conclusões \\
\hline $1^{15}$ & $\begin{array}{l}9 \text { homens } \\
\text { e } 8 \text { mulheres } \\
\text { (universitários) }\end{array}$ & $\begin{array}{l}\text { Flexibilidade do tornozelo } \\
\text { sobre a eficiência da perna. }\end{array}$ & Cinemática. & $\begin{array}{l}\text { A velocidade da ondulação } \\
\text { subaquática é afetada pela } \\
\text { mobilidade do tornozelo. }\end{array}$ \\
\hline $2^{14}$ & $\begin{array}{l}10 \text { homens } \\
\text { (competitivos) }\end{array}$ & $\begin{array}{l}\text { Diferenças no custo de energia } \\
\text { de crawl e costas. }\end{array}$ & $\begin{array}{l}\text { Medição de } \\
\text { oxigênio; Cinemetria } \\
\text { tridimensional. }\end{array}$ & $\begin{array}{l}\text { O crawl é menos dispendioso que o } \\
\text { nado costas no que se refere ao gasto } \\
\text { energético. }\end{array}$ \\
\hline $3^{16}$ & $\begin{array}{l}7 \text { homens e } \\
6 \text { mulheres } \\
\text { (competitivos) }\end{array}$ & $\begin{array}{l}\text { Nadadores iniciantes e } \\
\text { aumento da força do quadril. }\end{array}$ & $\begin{array}{l}\text { Medições fisiológicas; } \\
\text { Força e amplitude. }\end{array}$ & $\begin{array}{l}\text { Diferentes características fisiológicas } \\
\text { predizem o desempenho. }\end{array}$ \\
\hline $4^{17}$ & Revisão sistemática & $\begin{array}{l}\text { Propulsão com movimento } \\
\text { de pernas na ondulação } \\
\text { subaquática. }\end{array}$ & Revisão sistemática. & $\begin{array}{l}\text { Na literatura, as informações são } \\
\text { limitadas sobre os mecanismos } \\
\text { de propulsão na ondulação } \\
\text { subaquática. }\end{array}$ \\
\hline $5^{35}$ & $\begin{array}{l}49 \text { nadadores } \\
\text { (nível não descrito) }\end{array}$ & $\begin{array}{l}\text { Contribuição de membros } \\
\text { inferiores para os quatro nados. }\end{array}$ & $\begin{array}{l}\text { Células de carga; } \\
\text { Velocímetro } \\
(\mathrm{f}=5 \mathrm{oHz})\end{array}$ & $\begin{array}{l}\text { Os quatro nados exibiram } \\
\text { propriedades não lineares. O peito } \\
\text { e o borboleta têm padrões mais } \\
\text { complexos. }\end{array}$ \\
\hline $6^{36}$ & $\begin{array}{l}7 \text { homens } \\
\text { (competitivos) }\end{array}$ & $\begin{array}{l}\text { A ação das pernas no arrasto } \\
\text { ativo no nado livre. }\end{array}$ & $\begin{array}{l}\text { Células de carga; } \\
\text { Plataforma de força. }\end{array}$ & $\begin{array}{l}\text { Verificou-se que o coeficiente de } \\
\text { arrasto ativo é cerca de 1,6-1,9 vezes } \\
\text { maior que o das condições passivas. }\end{array}$ \\
\hline $7^{37}$ & $\begin{array}{l}72 \text { nadadores } \\
\text { e } 78 \text { jogadores de } \\
\text { futebol }\end{array}$ & $\begin{array}{l}\text { Diferenças na postura do pé } \\
\text { entre jogadores de futebol e } \\
\text { nadadores. }\end{array}$ & $\begin{array}{l}\text { Análise da postura do } \\
\text { pé. }\end{array}$ & $\begin{array}{l}\text { Houve diferenças estatisticamente } \\
\text { significativas }(p<0,001) \text { entre os } \\
\text { dois grupos. }\end{array}$ \\
\hline $8^{19}$ & $\begin{array}{l}3 \text { nadadores } \\
\text { (competitivos) }\end{array}$ & $\begin{array}{l}\text { Sistema de detecção } \\
\text { subaquático baseado em IMU. }\end{array}$ & $\begin{array}{l}\text { Sensores detecção } \\
\text { simultânea (IMU). }\end{array}$ & $\begin{array}{l}\text { O sistema proposto pode alcançar } \\
\text { uma precisão de classificação } \\
\text { satisfatória. }\end{array}$ \\
\hline $9^{38}$ & $\begin{array}{l}8 \text { mulheres } \\
\text { (amadoras) }\end{array}$ & $\begin{array}{l}\text { Eficiência de propulsão durante } \\
\text { a ondulação subaquática. }\end{array}$ & $\begin{array}{l}\text { Análise cinemática; } \\
\text { Eletromiografia de } \\
\text { superfície. }\end{array}$ & $\begin{array}{l}\text { A perna foi ineficiente quando o } \\
\text { nadador aumentou a frequência } \\
\text { de movimentos acima do esforço } \\
\text { máximo. }\end{array}$ \\
\hline $10^{39}$ & $\begin{array}{l}20 \text { nadadores } \\
\text { (elite) }\end{array}$ & $\begin{array}{l}\text { Custo metabólico: membros } \\
\text { superiores e inferiores. }\end{array}$ & $\begin{array}{l}\text { Medição da captação } \\
\text { de oxigênio. }\end{array}$ & $\begin{array}{l}\text { As pernas foram responsáveis por } \\
\text { uma porcentagem maior do custo } \\
\text { metabólico do que os membros } \\
\text { superiores. }\end{array}$ \\
\hline $11^{40}$ & $\begin{array}{l}26 \text { nadadores } \\
\text { (nível não descrito) }\end{array}$ & $\begin{array}{l}\text { Movimentos das pernas e dos } \\
\text { braços no nado peito. }\end{array}$ & Metrônomo. & $\begin{array}{l}\text { As flutuações da velocidade } \\
\text { intracíclica aumentaram com o } \\
\text { ritmo, enquanto a velocidade da } \\
\text { natação não diferiu. }\end{array}$ \\
\hline
\end{tabular}




\section{Sujeitos da pesquisa

$12^{24} 10$ nadadores (elite) $\begin{aligned} & \text { Desempenho ondulatório da } \\ & \text { natação subaquática. }\end{aligned}$

$\begin{array}{ll}\text { Coordenação das pernas e } & \text { Cinemática; } \\ \text { braços durante o nado Peito. } & \text { Lactímetro. }\end{array}$

Lactímetro.
A velocidade máxima do dedo do pé explicava $72 \%$ da variação da velocidade média.

$\begin{array}{ll} & 8 \text { mulheres } \\ 13^{41} \quad & \text { e } 18 \text { homens } \\ \text { (especialistas) }\end{array}$

\begin{tabular}{ll}
\hline $14^{18}$ & $\begin{array}{l}34 \text { nadadores (nível } \\
\text { não descrito) }\end{array}$ \\
\hline $15^{20}$ & $\begin{array}{l}5 \text { mulheres e } 4 \\
\text { homens } \\
\text { (elite) }\end{array}$ \\
\hline $16^{21} \quad \begin{array}{l}16 \text { nadadores (8 de } \\
\text { elite, } 8 \text { iniciantes) }\end{array}$
\end{tabular}

Coordenação propulsiva dos

membros e aceleração corporal Sensor inercial. na natação.

Coordenação muscular do nado peito.

Cinemática;
Eletromiografia de superfície.

Coordenação muscular: comparação entre elite e iniciantes.
Eletromiografia de superfície.
Diferenças quanto ao sexo, com relação à frequência cardíaca e no lactato sanguíneo, antes e depois da natação.
Ação específica durante a imersão do tronco e da cabeça com tempo da ação da perna no nado peito.

Foi observada uma diminuição nas diferentes fases da duração durante o alongamento e flexão do joelho.

Os padrões musculares individuais foram moderadamente semelhantes entre os grupos.

O treinamento competitivo de natação em longo prazo pode induzir um padrão eficaz de ativação muscular das pernas.

A carga articular do membro inferior estava dentro de $5 \%$ do peso corporal.

A redução na variância sugere ênfase nas diferenças interindividuais; técnica ondulatória e/ou antropometria.

A velocidade da natação não teve efeito significativo na duração relativa das fases de "braçada" e "pernada".

O modelo esclareceu a capacidade dos nadadores de moderar o

Cálculos de dinâmica. aumento do trabalho interno em altas frequências.

As principais atividades musculares foram observadas durante a fase de saída para realizar uma poderosa extensão de membros inferiores.

As contribuições relativas estimadas de "braçada" e "pernada" foram $70,3 \%$ versus $29,7 \%$ para homens e $66,6 \%$ contra $33,4 \%$ para mulheres. 


\begin{tabular}{|c|c|c|c|c|}
\hline & $\begin{array}{l}\text { Sujeitos da } \\
\text { pesquisa }\end{array}$ & Tema da pesquisa & Instrumentos & Principais conclusões \\
\hline $24^{29}$ & $\begin{array}{l}26 \text { nadadores } \\
\text { (competitivos) }\end{array}$ & $\begin{array}{l}\text { Força muscular do tornozelo e } \\
\text { flexibilidade no desempenho } \\
\text { das pernas. }\end{array}$ & Cinemática. & $\begin{array}{l}\text { A velocidade da ação das pernas do } \\
\text { borboleta pode ser aumentada por } \\
\text { exercícios de força muscular. }\end{array}$ \\
\hline $25^{11}$ & $\begin{array}{l}\text { Revisão da } \\
\text { literatura }\end{array}$ & $\begin{array}{l}\text { Métodos cinemáticos da ação } \\
\text { das pernas na ondulação } \\
\text { subaquática. }\end{array}$ & $\begin{array}{l}\text { Cinemática; } \\
\text { Sensores de } \\
\text { detecção simultânea. }\end{array}$ & $\begin{array}{l}\text { As várias IMUs podem ser } \\
\text { empregadas com segurança na } \\
\text { determinação da cinemática na } \\
\text { natação. }\end{array}$ \\
\hline $26^{43}$ & $\begin{array}{l}9 \text { nadadores (nível } \\
\text { não descrito) }\end{array}$ & $\begin{array}{l}\text { Coordenação intermembros e } \\
\text { custo de energia na natação. }\end{array}$ & $\begin{array}{l}\text { Medições fisiológicas; } \\
\text { cinemática. }\end{array}$ & $\begin{array}{l}\text { O padrão escolhido livremente } \\
\text { parecia mais econômico. }\end{array}$ \\
\hline $27^{27}$ & $\begin{array}{l}9 \text { nadadoras } \\
\text { (nível não descrito) }\end{array}$ & $\begin{array}{l}\text { O efeito da ação das pernas no } \\
\text { nado crawl. }\end{array}$ & Cinemática. & $\begin{array}{l}\text { Com a utilização das pernas, a } \\
\text { velocidade média da natação } \\
\text { aumentou significativamente. }\end{array}$ \\
\hline $28^{4}$ & $\begin{array}{l}8 \text { nadadores } \\
\text { (especialistas); } \\
\text { 10 nadadores } \\
\text { (recreativos) }\end{array}$ & $\begin{array}{l}\text { Indicadores de eficiência } \\
\text { e eficácia da natação entre } \\
\text { nadadores. }\end{array}$ & $\begin{array}{l}\text { Cinemática } \\
\text { tridimensional. }\end{array}$ & $\begin{array}{l}\text { Surgiram dois padrões de } \\
\text { coordenação entre nadadores } \\
\text { experientes e recreacionais. } \\
\text { Diferenças significativas na fase } \\
\text { relativa do início de um ciclo. }\end{array}$ \\
\hline $29^{44}$ & $\begin{array}{l}\text { 10 nadadores; } 10 \\
\text { atletas de atletismo } \\
\text { e voleibol }\end{array}$ & $\begin{array}{l}\text { Diferenças na força concêntrica } \\
\text { e excêntrica do joelho de } \\
\text { saltadores e não saltadores no } \\
\text { pouso. }\end{array}$ & $\begin{array}{l}\text { Cinemática; } \\
\text { Teste de força }\end{array}$ & $\begin{array}{l}\text { Os saltadores apresentaram torque } \\
\text { de extensão excêntrica do joelho } \\
\text { e torques de flexão concêntrica } \\
\text { significativamente maiores do que } \\
\text { os nadadores. }\end{array}$ \\
\hline $30^{45}$ & $\begin{array}{l}18 \text { nadadores } \\
\text { masculino (alto } \\
\text { nível) }\end{array}$ & $\begin{array}{l}\text { Ação das pernas em diferentes } \\
\text { velocidades na natação. }\end{array}$ & $\begin{array}{l}\text { Cinemática; } \\
\text { Cinética. }\end{array}$ & $\begin{array}{l}\text { Os resultados sugerem que o papel } \\
\text { propulsivo das pernas aumenta à } \\
\text { medida que a velocidade diminui. }\end{array}$ \\
\hline $31^{3^{1}}$ & $\begin{array}{l}7 \text { homens e } 5 \\
\text { mulheres } \\
\text { (nível não descrito) }\end{array}$ & $\begin{array}{l}\text { A contribuição da eficiência } \\
\text { da ondulação subaquática na } \\
\text { determinação do nado crawl. }\end{array}$ & $\begin{array}{l}\text { Cinemática } \\
\text { subaquática. }\end{array}$ & $\begin{array}{l}\text { Nos primeiros } 5 \text { a } 15 \text { metros } \\
\text { após a virada, a velocidade é } \\
\text { essencialmente sustentada pela } \\
\text { força gerada pelo nadador na parede } \\
\text { da piscina. }\end{array}$ \\
\hline $32^{46}$ & $\begin{array}{l}20 \text { nadadores } \\
\text { (nível não descrito) }\end{array}$ & $\begin{array}{l}\text { Relação entre diminuição } \\
\text { da velocidade de natação e } \\
\text { atividade muscular. }\end{array}$ & $\begin{array}{l}\text { Cinemática; } \\
\text { Eletromiografia de } \\
\text { superfície. }\end{array}$ & $\begin{array}{l}\text { A diminuição da velocidade na } \\
\text { natação esteve relacionada à } \\
\text { diminuição das atividades de vários. }\end{array}$ \\
\hline $33^{47}$ & $\begin{array}{l}114 \text { nadadores } \\
\text { (Jovens) }\end{array}$ & $\begin{array}{l}\text { Caracterização técnica do crawl } \\
\text { em nadadores de } 11 \text { a } 13 \text { anos de } \\
\text { idade. }\end{array}$ & Cinemática. & $\begin{array}{l}\text { Valores mais baixos, em todos os } \\
\text { parâmetros biomecânicos, do que os } \\
\text { nadadores mais velhos. }\end{array}$ \\
\hline $34^{48}$ & $\begin{array}{l}12 \text { nadadores } \\
\text { paraolímpicos }\end{array}$ & $\begin{array}{l}\text { Otimizando a pernada para } \\
\text { nadadores paraolímpicos por } \\
\text { meio de força. }\end{array}$ & $\begin{array}{l}\text { Sensor inercial; } \\
\text { Plataforma de força. }\end{array}$ & $\begin{array}{l}\text { A amplitude da ação das pernas } \\
\text { aumentou a força ativa líquida em } \\
25,1 \pm 10,6 \% \text {, embora a taxa da ação } \\
\text { das pernas tenha diminuído } 13,6 \pm \\
5,1 \% \text {. }\end{array}$ \\
\hline $35^{49}$ & $\begin{array}{l}8 \text { nadadores } \\
\text { (recreacionais); } \\
8 \text { (experientes) }\end{array}$ & $\begin{array}{l}\text { Coordenação do braço e nível } \\
\text { de desempenho no nado crawl } \\
\text { de } 400 \mathrm{~m} \text {. }\end{array}$ & Cinemática. & $\begin{array}{l}\text { O grupo de especialistas apresentou } \\
\text { valores significativamente mais altos } \\
\text { para velocidade e duração do nado. }\end{array}$ \\
\hline
\end{tabular}




\begin{tabular}{|c|c|c|c|c|}
\hline & $\begin{array}{c}\text { Sujeitos da } \\
\text { pesquisa }\end{array}$ & Tema da pesquisa & Instrumentos & Principais conclusões \\
\hline $36^{5^{0}}$ & $\begin{array}{l}24 \text { nadadores } \\
\text { (recreativos); } \\
24 \text { nadadores } \\
\text { (competitivos) }\end{array}$ & $\begin{array}{l}\text { Variabilidade interindividual } \\
\text { na coordenação do nado peito. }\end{array}$ & Cinemática. & $\begin{array}{l}\text { Foi observada maior variabilidade } \\
\text { interindividual entre os nadadores } \\
\text { recreativos do que entre os } \\
\text { nadadores competitivos. }\end{array}$ \\
\hline $37^{51}$ & $\begin{array}{l}26 \text { nadadores; } \\
32 \text { jogadores de } \\
\text { futebol }\end{array}$ & $\begin{array}{l}\text { Adaptação óssea às restrições } \\
\text { físicas inerentes a diferentes } \\
\text { esportes. }\end{array}$ & $\begin{array}{l}\text { DEXA - } \\
\text { Absorciometria } \\
\text { bifotónica de raio X }\end{array}$ & $\begin{array}{l}\text { A densidade mineral óssea foi } \\
\text { maior em jogadores de futebol em } \\
\text { comparação com nadadores. }\end{array}$ \\
\hline $3^{8^{52}}$ & $\begin{array}{l}22 \text { nadadores; } \\
11 \text { (recreativo); } 11 \\
\text { (elite) }\end{array}$ & $\begin{array}{l}\text { Coordenação da velocidade do } \\
\text { quadril e do braço na natação } \\
\text { do crawl. }\end{array}$ & $\begin{array}{l}\text { Cinemática; } \\
\text { Sistema de } \\
\text { velocímetro. }\end{array}$ & $\begin{array}{l}\text { A variabilidade média da velocidade } \\
\text { intracíclica foi menor nos nadadores } \\
\text { de elite do que nos nadadores } \\
\text { recreativos e ficou estável com o } \\
\text { ritmo de nado. }\end{array}$ \\
\hline $39^{28}$ & $\begin{array}{l}12 \text { nadadores } \\
\text { paraolímpicos }\end{array}$ & $\begin{array}{l}\text { Ação das pernas no nado; Livre } \\
\text { usando sensores inerciais. }\end{array}$ & $\begin{array}{l}\text { Sensores inerciais; } \\
\text { Cinemática. }\end{array}$ & $\begin{array}{l}\text { Geraram estimativas suficientes para } \\
\text { quantificar a taxa da ação das pernas } \\
\text { no nado livre. }\end{array}$ \\
\hline $40^{1}$ & $\begin{array}{l}198 \text { nadadores, } \\
\text { sendo } 32 \\
\text { experientes }\end{array}$ & $\begin{array}{l}\text { Opiniões de nadadores } \\
\text { especialistas e não especialistas } \\
\text { sobre a ondulação } \\
\text { subaquática. }\end{array}$ & $\begin{array}{l}\text { Questionário; } \\
\text { Análise de vídeo. }\end{array}$ & $\begin{array}{l}\text { Os participantes consideraram que } \\
\text { o nado submerso ondulatório era } \\
\text { menos atraente, menos poderoso } \\
\text { e menos rápido que os nados de } \\
\text { superfície. }\end{array}$ \\
\hline $41^{7}$ & $\begin{array}{l}14 \text { nadadores } \\
\text { paraolímpicos }\end{array}$ & $\begin{array}{l}\text { Quantificação dos padrões da } \\
\text { ação das pernas na natação } \\
\text { paraolímpica. }\end{array}$ & $\begin{array}{l}\text { Sensor inercial; } \\
\text { Plataforma de força. }\end{array}$ & $\begin{array}{l}\text { Os aumentos na taxa da ação } \\
\text { das pernas podem melhorar o } \\
\text { desempenho no nado livre. }\end{array}$ \\
\hline $42^{53}$ & $\begin{array}{l}1 \text { nadador; } \\
1 \text { nadadora }\end{array}$ & $\begin{array}{l}\text { Método computacional de } \\
\text { análise da hidrodinâmica } \\
\text { da ação das pernas no nado } \\
\text { subaquático. }\end{array}$ & $\begin{array}{l}\text { Software de } \\
\text { dinâmica de fluidos } \\
\text { computacional. }\end{array}$ & $\begin{array}{l}\text { A maior parte do impulso é } \\
\text { produzido pelos pés. A ação da } \\
\text { perna para baixo produz um } \\
\text { impulso muito maior que a ação da } \\
\text { perna para cima. }\end{array}$ \\
\hline $43^{54}$ & $\begin{array}{l}7 \text { (Velocistas); } \\
8 \text { (provas de fundo) }\end{array}$ & $\begin{array}{l}\text { Diferenças cinemáticas entre } \\
\text { velocistas e fundistas no nado } \\
\text { crawl. }\end{array}$ & Cinemática. & $\begin{array}{l}\text { Pouca evidência para sugerir que } \\
\text { nadadores de velocidade e fundistas } \\
\text { eram diferentes na técnica. }\end{array}$ \\
\hline $44^{55}$ & $\begin{array}{l}20 \text { nadadores } \\
\text { (elite); } \\
20 \text { (amadores) }\end{array}$ & $\begin{array}{l}\text { Parâmetros espaço-temporais e } \\
\text { coordenação braços-pernas. }\end{array}$ & Cinemática. & $\begin{array}{l}\text { Os nadadores de elite tinham maior } \\
\text { velocidade, comprimento e taxa de } \\
\text { braçadas e sincronização mais forte. }\end{array}$ \\
\hline $45^{56}$ & $\begin{array}{l}10 \text { nadadores } \\
\text { (habilidosos) }\end{array}$ & $\begin{array}{l}\text { Coordenação, variabilidade } \\
\text { e ruído biológico na ação da } \\
\text { perna. }\end{array}$ & Cinemática. & $\begin{array}{l}\text { Ângulos articulares desejados da } \\
\text { ação das pernas poderiam ser } \\
\text { treinados. }\end{array}$ \\
\hline $46^{57}$ & $\begin{array}{l}4 \text { homens e } \\
4 \text { mulheres }\end{array}$ & $\begin{array}{l}\text { Ação braços-pernas em nado } \\
\text { peito: nadadores de elite e } \\
\text { amadores. }\end{array}$ & Cinemática. & $\begin{array}{l}\text { Nadadores de elite de peito são } \\
\text { capazes de otimizar sua propulsão, } \\
\text { reduzindo sua fase de deslizamento. }\end{array}$ \\
\hline $47^{3}$ & $\begin{array}{l}9 \text { nadadores; } \\
8 \text { nadadoras (elite) }\end{array}$ & Um novo índice de propulsão. & Cinemática. & $\begin{array}{l}\text { A duração total da propulsão de } \\
\text { braços e pernas foi avaliada por um } \\
\text { novo índice de propulsão de peito } \\
\text { plano (IFBP). }\end{array}$ \\
\hline
\end{tabular}




\begin{tabular}{|c|c|c|c|c|}
\hline & $\begin{array}{l}\text { Sujeitos da } \\
\text { pesquisa }\end{array}$ & Tema da pesquisa & Instrumentos & Principais conclusões \\
\hline $48^{58}$ & $\begin{array}{l}16 \text { nadadores (nível } \\
\text { superior) }\end{array}$ & $\begin{array}{l}\text { Avaliação da coordenação } \\
\text { braços-pernas em nado peito. }\end{array}$ & Cinemática. & $\begin{array}{l}\text { Os nadadores de nível superior } \\
\text { apresentaram intervalos de tempo } \\
\text { curtos. }\end{array}$ \\
\hline $49^{59}$ & $\begin{array}{l}6 \text { nadadores (elite); } \\
6 \text { (amadores) }\end{array}$ & $\begin{array}{l}\text { Um estudo cinemático da } \\
\text { nadadeira na superfície. }\end{array}$ & Cinemática. & $\begin{array}{l}\text { Os nadadores de elites com } \\
\text { nadadeiras estavam mais aptos do } \\
\text { que os nadadores novatos. }\end{array}$ \\
\hline $50^{2}$ & $\begin{array}{l}11 \text { nadadores } \\
\text { (competitivos) }\end{array}$ & $\begin{array}{l}\text { Afundamento das pernas } \\
\text { pelo efeito rotacional da } \\
\text { flutuabilidade no crawl. }\end{array}$ & $\begin{array}{l}\text { Cinemática } \\
\text { tridimensional. }\end{array}$ & $\begin{array}{l}\text { O torque flutuante médio, durante } \\
\text { o ciclo de braçada, foi direcionado } \\
\text { para elevar as pernas e abaixar a } \\
\text { cabeça. }\end{array}$ \\
\hline $51^{60}$ & $\begin{array}{l}43 \text { nadadores } \\
\text { (diferentes níveis) }\end{array}$ & $\begin{array}{l}\text { Descrição e utilidade de um } \\
\text { novo índice de coordenação } \\
\text { para o crawl. }\end{array}$ & Cinemática. & $\begin{array}{l}\text { A duração das fases propulsivas } \\
\text { aumentou significativamente com o } \\
\text { aumento da velocidade. }\end{array}$ \\
\hline $52^{5}$ & $\begin{array}{l}8 \text { nadadores (nível } \\
\text { não descrito) }\end{array}$ & $\begin{array}{l}\text { Contribuição relativa de braços } \\
\text { e pernas em natação de } 25 \mathrm{~m} \text {. }\end{array}$ & Cinemática. & $\begin{array}{l}\text { A contribuição real da ação das } \\
\text { pernas na natação foi de } 10 \% \text { na } \\
\text { velocidade máxima. }\end{array}$ \\
\hline $53^{61}$ & Artigo de opinião & $\begin{array}{l}\text { A biomecânica da natação: o } \\
\text { ombro e o joelho. }\end{array}$ & Artigo de opinião. & $\begin{array}{l}\text { A ação das pernas gera forças que } \\
\text { visam superar o arrasto. }\end{array}$ \\
\hline $54^{10}$ & $\begin{array}{l}18 \text { nadadores } \\
\text { (competitivos) }\end{array}$ & $\begin{array}{l}\text { Forças e sua relação com o } \\
\text { desempenho. }\end{array}$ & $\begin{array}{l}\text { Célula de carga; } \\
\text { Nado atado. }\end{array}$ & $\begin{array}{l}\text { Correlação positiva entre a força } \\
\text { média e a velocidade. }\end{array}$ \\
\hline $55^{62}$ & $\begin{array}{l}23 \text { nadadores } \\
\text { (especialistas) }\end{array}$ & $\begin{array}{l}\text { Patologia no joelho do nadador } \\
\text { de peito. }\end{array}$ & Cinemática. & $\begin{array}{l}\text { O joelho deve ser direcionado para } \\
\text { corrigir a ação da perna do nadador. }\end{array}$ \\
\hline
\end{tabular}

\section{DISCUSSÃO}

Os estudos apresentaram como média amostral o valor de $26 \pm 36$ indivíduos, com valores mínimos e máximos de 1 até 198 sujeitos, respectivamente. Como os artigos apresentaram uma grande distribuição, optou-se também pelas medidas centrais de moda e mediana, nas quais em ambas o valor foi de 17 indivíduos. Isso demonstra que a força amostral dos estudos é limitada, além de uma heterogeneidade na coleta das amostras. Em mais um levantamento quantitativo, realizado por este estudo, pôde-se observar que 11 artigos tiveram como objeto de estudo a ação das pernas no nado peito. Isso demonstra a importância dada a essa ação nesse nado. $\mathrm{O}$ nado submerso também apresentou expressão nos estudos, já que foram encontrados 10 artigos sobre tal tema.

Quanto ao nível técnico dos nadadores, observou-se uma aleatoriedade nos resultados, tanto nas definições que os artigos usam para classificar o nível de seus sujeitos quanto na quantidade desses indivíduos. Alguns estudos, $5,12,19,20,23,27,36,38,42,53$ acabaram por avaliar poucos indivíduos; isso se deve ao fato de que, no ambiente aquático, as pesquisas tornam-se difíceis de serem realizadas. ${ }^{63}$

Quanto às produções, no decorrer do tempo foi possível identificar que estas se distribuem uniformemente. O primeiro estudo descrito nesta revisão foi em 1980 [62]. A partir 
de meados de 2000, nota-se uma crescente produção de conhecimento nessa área. No que se refere aos instrumentos utilizados, a cinemática ainda é a ferramenta mais empregada, sendo ela tridimensional ou bidimensional. Outras análises também fazem uso da cinética com plataformas de força, ${ }^{7,36}$ e células de cargas ${ }^{8,10,35}$ também aparecem com frequência. A grande mudança apresentada no transcorrer dos anos foi o implemento de tecnologias de análise por softwares, como a dinâmica de fluidos computacionais (CFD) $)^{12,53}$ e a utilização de centrais inerciais ${ }^{11,18,28,38}$ que permitem a coleta de variáveis, por telemetria e instantaneamente. A técnica da eletromiografia também está cada vez mais comum nos estudos dos membros inferiores na natação. ${ }^{20-22,38,42,46}$

Com relação aos temas, pode-se perceber que a maioria dos artigos avaliou as fases dos movimentos das pernas e dos braços na natação, como as flutuações de velocidade intracíclica e coordenação entre estes. ${ }^{3,18,20,26,40,41,52,55,56,58}$ Ainda nas coordenações, alguns estudos fizeram comparações entre nadadores de elite e iniciantes. $4,22,27,42,43,50,57,60$

As variáveis fisiológicas, em detrimento das biomecânicas, também foram bem estudadas. Os artigos buscaram diferenças na cinemática e no custo de energia entre os nados e a utilização dos membros inferiores. 14,16,35,39 Também foi apresentada a contribuição das pernas para os quatro nados competitivos, buscando a frequência da ação das pernas na eficiência de propulsão e na coativação muscular durante a ondulação subaquática. ${ }^{38}$ Ainda, alguns estudos se atentaram para a relação entre diminuição da velocidade de natação e atividade muscular durante o nado, o que pode ser traduzida como fadiga. ${ }^{46,48}$
Relações entre a cinemática e o desempenho ondulatório da natação subaquática foram abordadas em alguns estudos. ${ }^{5,8,31,45}$ Destes, buscava-se a contribuição relativa entre braços e pernas. No estudo de Connaboy et al. ${ }^{25}$ a busca foi pelas principais determinantes cinemáticas da natação subaquática. Também foram incluídas nas avaliações cinemáticas os efeitos da ação das pernas no arrasto ativo na natação. ${ }^{36,59}$ Essa busca contou, ainda, com as diferenças entre velocistas e fundistas no nado crawl; 54 a caracterização técnica da ação das pernas do crawl em nadadores de 11 a 13 anos de idade; 47 e em como otimizar os membros inferiores para nadadores paraolímpicos por meio de medidas de força. ${ }^{7,48,62}$

Com relação às forças, os estudos de Lauer, Olstad, Minetti, Kjendlie e Pouard, ${ }^{23}$ Lauer, Rouard e Vilas-Boas ${ }^{12}$ e Yeater, Martin, White e Gilson ${ }^{10}$ levantaram dados das forças articulares do membro superior e dos movimentos subaquáticos, além de como prever o trabalho mecânico interno da natação. Ainda no contexto força, alguns estudos ${ }^{19,28,53}$ investigaram as forças do nado atado no crawl, peito e costas, e sua relação com a ação das pernas na natação e o desempenho competitivo.

Entre os artigos encontrados, também foram observado diferentes esportes comparados com a ação da natação. Avaliaram, por exemplo, se o tipo de esporte praticado influencia a postura do pé e o ângulo do joelho ${ }^{37,44}$ e se as adaptações da geometria óssea e da força às restrições físicas inerentes aos esportes possuem diferenças entre atletas de futebol e de natação. ${ }^{51}$ Ainda, quanto à abordagem de determinados artigos, estes verificaram se a flexibilidade da articulação do tornozelo afeta a eficiência da ação das pernas no movimento subaquático ${ }^{15,29} \mathrm{e}$ o efeito rotacional da flutuabilidade no crawl com relação 
ao afundamento das pernas. ${ }^{2}$ Neste trabalho, foram incluídas duas revisões que se baseavam nos movimentos de pernas na ondulação subaquática. ${ }^{11,17}$

Os principais resultados que os estudos encontraram serão apresentados e discutidos na sequência. Com o objetivo de levantar o "estado da arte" sobre a utilização dos membros inferiores durante o nado, pode-se observar que as contribuições relativas estimadas das ações dos braços e das pernas, respectivamente, foram $70,3 \%$ versus $29,7 \%$ para homens e $66,6 \%$ contra $33,4 \%$ para mulheres. ${ }^{8}$ Esses dados já são maiores que os encontrados por Deschodt, Arsac e Rouard ${ }^{5}$ que limitavam as pernas a meros $10 \%$.

Evidências recentes sugerem que a propulsão é gerada em conjunto com a formação de vórtices, ${ }^{17}$ sendo um dos fatores mais importantes no desempenho da natação. A formação do vórtice, como elemento propulsivo essencial no deslocamento do nadador, possibilita não apenas estimar, por meio de modelos matemáticos, mas também quantificar sua eficiência, relacionando-o com a performance do nadador. Dessa forma, pode ser um referencial na validação de modelos computacionais. ${ }^{2}$

Sabe-se que a propulsão é gerada a partir dos membros superiores e inferiores, mas pouco se conhece sobre os mecanismos de propulsão a partir dos movimentos dos membros inferiores durante a ação das pernas. ${ }^{17}$ Infelizmente, na natação as pernas são frequentemente percebidas como um aspecto não essencial da propulsão aquática, ${ }^{1}$ porém, apesar de muitos não compreenderem, a otimização das ações das pernas na natação é altamente importante no desempenho competitivo, ${ }^{19}$ especialmente na natação subaquática. ${ }^{24} \mathrm{Um}$ dos motivos dessa condição é que foram encontradas informações limitadas sobre os mecanismos de propulsão dos membros inferiores. ${ }^{17}$ Os dados relatados no estudo de Zamparo, Vicentini, Scattolini, Rigamonti e Bonifazi ${ }^{31}$ indicam que, nos primeiros 5 a 15 metros após a virada, a velocidade é essencialmente sustentada pela força gerada pelo nadador na parede da piscina, e também indica a importância de uma boa execução do movimento ondulatório subaquático e de uma hidrodinâmica adequada. Assim, é certo que o efeito positivo da ação das pernas influencia a velocidade da natação, além da geração direta, e óbvia, de forças propulsivas a partir das pernas. ${ }^{27}$ Em um estudo de Gatta, Cortesi e Di Michele, ${ }^{45}$ and selected kinematic indices were evaluated at 1.2 and $2.0 \mathrm{~m} / \mathrm{s}$. The highest power $(54+/-8 \mathrm{~W}$ pode-se entender que o papel propulsivo das pernas aumenta à medida que a velocidade da natação diminui. Isso parece uma estratégia para manter as velocidades, apesar da redução no desempenho. Como estratégia, o estudo de Fulton, Pyne e Burkett ${ }^{7}$ identificou que houve uma redução substancial na frequência dos batimentos das pernas no terceiro segmento de $25 \mathrm{~m}$. Houve um aumento de 10,6\% no número das ações das pernas no quarto segmento de $25 \mathrm{~m}$ para uma prova de $100 \mathrm{~m}$ livres. Isso demonstra uma técnica de "resguardar-se" para o final. Neste estudo também se constatou que os aumentos na taxa de ação das pernas podem melhorar o desempenho da natação no nado livre.

Das condições que propiciam a melhora no desempenho, é amplamente aceito que a velocidade da natação é determinada por uma combinação de duas forças externas que atuam no nadador: a força propulsora, obtida por meio das ações segmentares dos membros do nadador, e a força de arrasto hidrodinâmica, em oposição ao seu deslocamento. ${ }^{64}$ Se as pernas parecem tão 
eficientes, então por que são desacreditadas? É certo que o custo energético para manter a intensidade do batimento das pernas é alto. No estudo de Morris, Osborne, Shephard, Jenkins e Skinner ${ }^{39}$ a contribuição da velocidade dos membros superiores foi maior que a dos membros inferiores, mesmo apresentando uma porcentagem menor do custo metabólico que os membros inferiores. Também no estudo de Narita, Nakashima e Takagi ${ }^{36}$ se verificou que o coeficiente de arrasto ativo é cerca de 1,6-1,9 vezes maior que o das condições passivas quanto à utilização das pernas. Aqui cabe uma ressalva, uma vez que os dados partiram de apenas sete nadadores. Em mais um estudo que utilizou um baixo número amostral (oito nadadoras de nível amador), identificou-se que a propulsão, quanto ao padrão de ativação muscular, se tornou ineficiente quando o nadador aumentou a frequência da ação das pernas acima do esforço máximo. $3^{8}$ Outro estudo que deu ênfase à utilização dos membros inferiores também apresentou aumento significativo na frequência cardíaca e no lactato sanguíneo depois da natação. ${ }^{41}$

Como visto, resultados demonstram que diferentes características fisiológicas predizem o desempenho, ${ }^{16}$ e que a escolha do movimento é um fator intrínseco e está ligado à individualidade do nadador. Assim, também são os ganhos com mobilidade e flexibilidade que, apesar de serem treináveis, são dependentes dos fatores genéticos dos nadadores. E se essa variável é importante e a velocidade da ação das pernas é dependente dela, ${ }^{15}$ pode-se dizer que pouco se desenvolve nesse quesito. Para corroborar, Gonjo et al. ${ }^{14}$ intra-cycle velocity fluctuation, three-dimensional wrist and ankle speeds, and vertical and lateral ankle range of motionrelatam em seu estudo que os nadadores tiveram velocidades tridimensionais mais lentas no tornozelo sob a água e menor amplitude de movimento vertical também no tornozelo para o nado crawl. Essa condição pode predizer que os fatores genéticos são limitantes para alguns nadadores, sendo que, como algumas provas demandam maiores mobilidades articulares, e estas são intrínsecas ao indivíduo, cabe dizer que a prova escolhe o nadador, não o nadador escolhe a prova. Com relação a essa contribuição dos membros inferiores, o nado peito e o borboleta têm padrões mais complexos, porém, mais previsíveis do que o nado costas e o crawl. 35

Sabendo da importância de manter um bom alinhamento para minimizar o arrasto resistivo na natação, percebe-se que há uma escassez na literatura relacionada ao efeito das assimetrias técnicas nas rotações do corpo em torno de um eixo vertical (guinada). ${ }^{6}$ Nesse sentido, a flexibilidade do tornozelo é uma variável fundamental para obter uma alta velocidade na natação subaquática ondulada, ${ }^{5}$ haja vista que tal esporte é capaz de alterar a conformação do pé e joelho, com afinidade à pronação e um ângulo Q com tendência ao valgo, respectivamente. ${ }^{37}$ Ainda, de acordo com os resultados encontrados por Willems, Cornelis, Deurwaerder, Roelandt e Mits, ${ }^{29}$ indivíduos com flexibilidade restrita nesse seguimento podem se beneficiar de um programa de flexibilidade, e a velocidade da ação das pernas pode ser aumentada por exercícios de força muscular no tornozelo, resultando em maior eficiência de propulsão. Isso porque o torque flutuante - e talvez as forças geradas pelas ações das pernas - atuam neutralizando o torque gerado pelas forças hidrodinâmicas que agem nas mãos, de modo que aumentam a velocidade média dos nadadores, ${ }^{27}$ por manterem o alinhamento horizontal do corpo. ${ }^{2}$ Nesse contexto, vê-se que o uso da modelagem musculoesquelética como ferramenta para analisar o desempenho esportivo 
está aumentando. Isso normalmente envolve a simulação do movimento de um atleta, bem como as cargas externas que ele experimenta, além da avaliação das atividades musculares com relação à cinemática especificada. ${ }^{11}$

Aprofundar esses estudos na identificação da relação existente entre membros superiores e inferiores é extremamente necessário, visto que, segundo Vaz, Olstad, Cabri, Kjendlie, Pezarat-Correia e Hug, ${ }^{21}$ a organização sinérgica da coordenação muscular durante o nado peito não é profundamente afetada pela experiência, mas sim por ajustes específicos de tempo entre membros inferiores e superiores. Komar, Sanders, Chollet e Seifert ${ }^{4}$ ainda trazem que os padrões de coordenação entre nadadores experientes e recreacionais são diferentes, alternando significativamente na fase relativa no início de um ciclo, que afetará as fases seguintes, o que resulta em um tempo mais tardio de deslocamento da ativação muscular nos nadadores recreativos em todas as velocidades. ${ }^{22}$

Em um estudo adjacente, percebeu-se que a nadadora mais qualificada da amostra foi a única a solicitar seus músculos durante a fase do deslizamento para alcançar ativamente uma melhor aerodinâmica. ${ }^{42}$ Tais diferenças nas estratégias de EMG, entre um grupo de elite, destacam a importância de considerar os parâmetros musculares utilizados para controlar efetivamente a intensidade de ativação entre as fases para uma ação das pernas mais eficiente..$^{22}$

A coordenação dos experientes, portanto, está associada à maior eficácia da natação e maior distância percorrida pelo centro de massa durante cada fase do ciclo. ${ }^{4}$ Logo, o desempenho qualificado depende de uma coordenação otimizada, que resulta em um comportamento eficaz, exibindo flexibilidade, principalmente no momento da fase de deslizamento, para se adaptar a diferentes velocidades. ${ }^{4,52}$ Em nadadores unilaterais, a exemplo dos amputados, a capacidade de dissociar os movimentos dos braços e das pernas demonstra que, por causa de sua deficiência física, esses indivíduos adaptam funcionalmente sua organização motora ao nado. ${ }^{26}$

Corroborandoesses achados, as correlações positivas entre vários músculos identificadas por Ikuta, Matsuda, Yamada, Kida, Oda e Moritani, ${ }^{46}$ sugerem que a diminuição da velocidade na natação está relacionada à diminuição das atividades de músculos que se coordenam entre si, e que uma estratégia compensatória ocorre em maior parte nos $50 \mathrm{~m}$. Levando em conta a importância e a contribuição dos membros inferiores no desempenho da natação, percebese que o treinamento competitivo em longo prazo pode induzir um padrão eficaz de ativação muscular das pernas, elevando o desempenho dos nadadores. $^{22}$

Essas descobertas fornecem uma nova visão das adaptações dos nadadores em um evento de média distância. ${ }^{49}$ Este estudo identificou que nadadores de nível superior apresentam intervalos de tempo curtos no ciclo do nado, indicando a continuidade das ações de braços e pernas. ${ }^{18}$ A consciência da importância dessas varáveis pode levar ao aprimoramento da capacidade dos nadadores de moderar o aumento do trabalho interno em altas frequências. Tal estratégia de minimização de energia nunca foi observada antes em humanos, mas está presente na locomoção animal de quadrúpedes e polvos. ${ }^{23}$

A medição desses intervalos, por conseguinte, fornece uma avaliação pertinente acerca das habilidades de adaptar a coordenação 
braços-pernas às restrições biomecânicas..$^{8}$ Em razão das dificuldades e diversos fatores que devem ser considerados no momento das análises, a natação é um dos tópicos mais complexos da biomecânica. ${ }^{66}$ Os estudos verificados nesta revisão compreendem a utilização de diversos instrumentos, indo desde abordagens clássicas, como a cinemática e cinética, com uso de plataformas de força, células de carga e centrais inerciais, até eletromiografia, que também demonstra grande potencial para aplicação em análises na natação. Outro método que vem sendo utilizado nesse âmbito é a dinâmica dos fluidos computacional (CFD), que engloba os desafios de modelagem do nadador, sendo mais realista por permitir simulações, diferente dos métodos convencionais de varreduras a laser ou imagens de vídeo. ${ }^{67}$

Além dessas abordagens, resultados preliminares mostram que o sistema de detecção baseado em IMU pode ser útil na análise de movimento. ${ }^{19}$ Verificou-se que os ângulos do corpo derivados da IMU exibem concordância estreita com o processo de digitalização manual. Sugere-se, assim, que as várias IMUs possam ser empregadas com segurança na determinação da cinemática na natação."

Ressalva-se também que falta modelagem para geração de dados de dinâmica, inversa em decorrência da dificuldade em medir forças hidrodinâmicas em condições dinâmicas. ${ }^{12}$ Não obstante, o mais importante é reconhecer os possíveis ganhos advindos das ondulações corporais, bem como aprimorar ações específicas durante a imersão na água, ${ }^{18}$ com vistas ao alcance de melhores intervalos de tempo em provas de natação.

\section{CONSIDERAÇÕES FINAIS}

Como conclusão, pode-se observar que os estudos sobre a utilização dos membros inferiores na natação possuem, em grande maioria, um número amostral baixo. Além disso, os artigos contam com a descrição heterogênea dos níveis dos participantes dos estudos.

Os trabalhos que investigam os membros inferiores na natação tiveram um aumento expressivo a partir de meados do ano 2000. Com relação às técnicas de análise, a cinemetria ainda é a mais empregada, seguida da dinamometria por células de carga e plataformas de força. Houve um incremento nas pesquisas nessa área com a introdução de novas tecnologias, como os sensores inerciais e as análises por dinâmica de fluidos computacionais. A técnica da análise da ativação muscular por eletromiografia também tem demostrado um desenvolvimento nas produções que estudam a utilização das pernas na natação.

Também se pode observar que o nado peito e as ondulações subaquáticas são as variáveis mais estudadas dentro dos temas propostos pelos artigos.

A ação dos membros inferiores na natação é subestimada e pouco compreendida entre os seus praticantes e pesquisadores. Quebrar esse paradigma é essencial para entender melhor os determinantes dos custos mecânicos da natação e a geração de energia nos movimentos aquáticos gerados pelas pernas.

Ademais, preconiza-se examinar a eficácia de outras variáveis antropométricas, cinemáticas e de coordenação para entender melhor a produção da velocidade máxima na natação e considerar a importância de técnicas individuais de natação subaquática ondulatória ao interpretar os dados. 
Pesquisas futuras devem avançar no entendimento da importância dos membros inferiores para a natação, examinando aspectos CONFLITO DE INTERESSES ligados à geração de força por esses seguimentos, além de relacionarem aspectos individuais que são determinantes para esse movimento.

Os autores declaram não haver conflito de interesses.

\section{REFERÊNCIAS}

1. Collard L, Oboeuf A. Comparison of expert and nonexpert swimmers' opinions about the value, potency, and activity of four standard swimming strokes and underwater undulatory swimming. Percept Mot Skills. 2009 Apr;108(2):491-8.

2. Yanai T. Rotational effect of buoyancy in frontcrawl: Does it really cause the legs to sink? J Biomech. 2001 Feb;34(2):235-43.

3. Seifert L, Chollet D. A new index of flat breaststroke propulsion: a comparison of elite men and women. J Sports Sci. 2005 Mar;23(3):309-20.

4. Komar J, Sanders RH, Chollet D, Seifert L. Do qualitative changes in interlimb coordination lead to effectiveness of aquatic locomotion rather than efficiency? J Appl Biomech. 2014;30(2):189-96.

5. Deschodt VJ, Arsac LM, Rouard AH. Relative contribution of arms and legs in humans to propulsion in 25-m sprint front-crawl swimming. Eur J Appl Physiol Occup Physiol. 1999 Aug;80(3):1929.

6. Marinho DA, Barbosa TM, Kjendlie PL, Vilas-Boas JP, Alves FB, Rouboa AI, et al. Swimming simulation: A new tool for swimming research and practical applications. LNCSE. 2009;72:33-61.

7. Fulton SK, Pyne DB, Burkett B. Quantifying freestyle kick-count and kick-rate patterns in Paralympic swimming. J Sports Sci. 2009 Nov;27(13):1455-61.

8. Morouco PG, Marinho DA, Izquierdo M, Neiva H, Marques MC. Relative Contribution of Arms and Legs in 30 s Fully Tethered Front Crawl Swimming. Biomed Res Int. 2015;2015(Spec No).

9. Adesida Y, Papi E, McGregor AH. Exploring the role of wearable technology in sport kinematics and kinetics: A systematic review. Sensors. 2019 Apr;19(7):1597.

10. Yeater RA, Martin RB, White MK, Gilson KH. Tethered swimming forces in the crawl, breast and back strokes and their relationship to competitive performance. J Biomech. 1981;14(8):527-37. 
11. Phillips CWG, Forrester AIJ, Hudson DA, Turnock SR. Comparison of kinematic acquisition methods for musculoskeletal analysis of underwater flykick. In: James D, Choppin S, Allen T, Wheat J, Fleming P. Procedia Engineering. 2014;72:56-61.

12. Lauer J, Rouard AH, Vilas-Boas JP. Upper limb joint forces and moments during underwater cyclical movements. J Biomech [Internet]. 2016;49(14):3355-61. Available from: http://dx.doi. org/10.1016/j.jbiomech.2016.08.027

13. Strzala M, Krezalek P, Kucia-Czyszczon K, Ostrowski A, Stanula A, Tyka AK, et al. Coordination and propulsion and non-propulsion phases in 100 meter breaststroke swimming. Acta Bioeng Biomech. 2014;16(4):83-9.

14. Gonjo T, McCabe C, Sousa A, Ribeiro J, Fernandes RJ, Vilas-Boas JP, et al. Differences in kinematics and energy cost between front crawl and backstroke below the anaerobic threshold. Eur J Appl Physiol. 2018;118(6):1107-18.

15. Shimojo H, Nara R, Baba Y, Ichikawa H, Ikeda Y, Shimoyama Y. Does ankle joint flexibility affect underwater kicking efficiency and three-dimensional kinematics? J Sports Sci. 2019 Oct;37(20):2339-46.

16. Beethe AZ, Nagle EF, Lovalekar M, Nagai T, Nindl BC, Connaboy C. Improvement of Flutter-Kick Performance in Novice Surface Combat Swimmers With Increased Hip Strength. Int J Sports Physiol Perform. 2018 Nov;1-8.

17. Andersen JT, Sanders RH. A systematic review of propulsion from the flutter kick - What can we learn from the dolphin kick? J Sports Sci. 2018 Sept;36(18):2068-75.

18. Strzała M, Stanula A, Ostrowski A, Kaca M, Krzałek P, Głodzik J, et al. Propulsive limb coordination and body acceleration in sprint breaststroke swimming. J Sports Med Phys Fitness. 2017;57(12):1564-71.

19. Zhang ZD, Xu DF, Zhou ZH, Mai JG, He ZK, Wang QN, et al. IMU-Based Underwater Sensing System for Swimming Stroke Classification and Motion Analysis. In: Ieee International Conference on Cyborg and Bionic Systems. October 17-19, 2017. Beijing. China: Friendship Hotel; 2017. p. 268-272.

20. Olstad BH, Vaz JR, Zinner C, Cabri JMH, Kjendlie P-L. Muscle coordination, activation and kinematics of world-class and elite breaststroke swimmers during submaximal and maximal efforts. J Sports Sci. 2017 June;35(11):1107-17.

21. Vaz JR, Olstad BH, Cabri J, Kjendlie P-L, Pezarat-Correia P, Hug F. Muscle coordination during breaststroke swimming: Comparison between elite swimmers and beginners. J Sports Sci. 2016 Oct;34(20):1941-48. 
22. Matsuda Y, Hirano M, Yamada Y, Ikuta Y, Nomura T, Tanaka H, et al. Lower muscle co-contraction in flutter kicking for competitive swimmers. Hum Mov Sci. 2016 Feb;45:40-52.

23. Lauer J, Olstad BH, Minetti AE, Kjendlie P-L, Rouard AH. Breaststroke swimmers moderate internal work increases toward the highest stroke frequencies. J Biomech. 2015;48(12):3012-6.

24. Higgs AJ, Pease DL, Sanders RH. Relationships between kinematics and undulatory underwater swimming performance. J Sport Sci. 2017;35(10):995-1003.

25. Connaboy C, Naemi R, Brown S, Psycharakis S, McCabe C, Coleman S, et al. The key kinematic determinants of undulatory underwater swimming at maximal velocity. J Sports Sci. 2016;34(11):1036-43.

26. Osborough C, Daly D, Payton C. Effect of swim speed on leg-to-arm coordination in unilateral arm amputee front crawl swimmers. J Sports Sci. 2015;33(14):1523-31.

27. Gourgoulis V, Boli A, Aggeloussis N, Toubekis A, Antoniou P, Kasimatis P, et al. The effect of leg kick on sprint front crawl swimming. J Sports Sci. 2014;32(3):278-89.

28. Fulton SK, Pyne DB, Burkett B. Validity and reliability of kick count and rate in freestyle using inertial sensor technology. J Sports Sci. 2009 Aug;27(10):1051-8.

29. Willems TM, Cornelis JAM, De Deurwaerder LEP, Roelandt F, De Mits S. The effect of ankle muscle strength and flexibility on dolphin kick performance in competitive swimmers. Hum Mov Sci. 2014 Aug;36:167-76.

30. Veiga S, Roig A. Underwater and surface strategies of $200 \mathrm{~m}$ world level swimmers. J Sports Sci. 2016;34(8):766-71.

31. Zamparo P, Vicentini M, Scattolini A, Rigamonti M, Bonifazi M. The contribution of underwater kicking efficiency in determining \&quot; turning performance\&quot; in front crawl swimming. J Sport Med Phys Fit. 2012;52(5):457-64.

32. Cordeiro AM, Oliveira GM, Rentería JM, Guimarães CA. Revisão sistemática: uma revisão narrativa. Rev. Col. Bras. Cir. 2007;34(6).

33. Gil AC. Métodos e Técnicas de Pesquisa Social. São Paulo: Atlas; 2008.

34. Silva EL, Menezes EM. Metodologia da Pesquisa e Elaboração de Dissertação. 4a ed. São Paulo: Portal; 2005. 
35. Bartolomeu RF, Costa MJ, Barbosa TM. Contribution of limbs\&\#039; actions to the four competitive swimming strokes: a nonlinear approach. J Sport Sci. 2018;36(16):1836-45.

36. Narita K, Nakashima M, Takagi H. Effect of leg kick on active drag in front-crawl swimming: Comparison of whole stroke and arms-only stroke during front-crawl and the streamlined position. J Biomech. 2018 July;76:197-203.

37. Lopezosa-Reca E, Gijon-Nogueron G, Garcia-Paya I, Ortega-Avila AB. Does the type of sport practised influence foot posture and knee angle? Differences between footballers and swimmers. Res Sport Med. 2018;26(3):345-53.

38. Yamakawa KK, Shimojo H, Takagi H, Tsubakimoto S, Sengoku Y. Kinematic and EMG data during underwater dolphin kick change while synchronizing with or without synchronization of kick frequency with the beat of a metronome. Data Br. 2017;14:28-31.

39. Morris KS, Osborne MA, Shephard ME, Jenkins DG, Skinner TL. Velocity, Oxygen Uptake, and Metabolic Cost of Pull, Kick, and Whole-Body Swimming. Int J Sports Physiol Perform. 2017 Sept;12(8):1046-51.

40. Van Houwelingen J, Roerdink M, Huibers AV, Evers LLW, Beek PJ. Pacing the phasing of leg and arm movements in breaststroke swimming to minimize intra-cyclic velocity fluctuations. PLoS One. 2017;12(10):eo18616o-eo18616o.

41. Oxford SW, James RS, Price MJ, Payton CJ, Duncan MJ. Changes in kinematics and arm-leg coordination during a 100-m breaststroke swim. J Sports Sci. 2017;35(16):1658-65.

42. Guignard B, Olstad BH, Simbana ED, Lauer J, Kjendlie P-L, Rouard AH. Different Muscle-Recruitment Strategies Among Elite Breaststrokers. Int J Sports Physiol Perform. 2015 Nov;10(8):1061-5.

43. Seifert L, Komar J, Crettenand F, Dadashi F, Aminian K, Millet GP. Inter-limb coordination and energy cost in swimming. J Sci Med Sport. 2014;17(4):439-44.

44. Wu X, Zhang S, Liu Y, Zhang D, Xie B. Do knee concentric and eccentric strength and sagittal-plane knee joint biomechanics differ between jumpers and non-jumpers in landing? Hum Mov Sci. 2013;32(6):1299-309.

45. Gatta G, Cortesi M, Di Michele R. Power production of the lower limbs in flutter-kick swimming. Sport Biomech. 2012 Nov;11(4):480-91.

46. Ikuta Y, Matsuda Y, Yamada Y, Kida N, Oda S, Moritani T. Relationship between decreased swimming velocity and muscle activity during 200-m front crawl. Eur J Appl Physiol. 2012;112(9):341729. 
47. Silva A, Figueiredo P, Soares S, Seifert L, Vilas-Boas JP, Fernandes RJ. Front crawl technical characterization of 11- to 13-year- old swimmers. Pediatr Exerc Sci. 2012 Aug;24(3):409-19.

48. Fulton SK, Pyne D, Burkett B. Optimizing kick rate and amplitude for Paralympic swimmers via net force measures. J Sports Sci. 2011 Feb;29(4):381-7.

49. Schnitzler C, Seifert L, Chollet D. Arm coordination and performance level in the 40o-m front crawl. Res Q Exerc Sport. 2011 Mar;82(1):1-8.

50. Seifert L, Leblanc H, Herault R, Komar J, Button C, Chollet D. Inter-individual variability in the upper-lower limb breaststroke coordination. Hum Mov Sci. 2011 June;30(3):550-65.

51. Ferry B, Duclos M, Burt L, Therre P, Le Gall F, Jaffre C, et al. Bone geometry and strength adaptations to physical constraints inherent in different sports: comparison between elite female soccer players and swimmers. J Bone Miner Metab. 2011 May;29(3):342-51.

52. Schnitzler C, Seifert L, Alberty M, Chollet D. Hip velocity and arm coordination in front crawl swimming. Int J Sports Med. 2010 Dec;31(12):875-81.

53. Von Loebbecke A, Mittal R, Mark R, Hahn J. A computational method for analysis of underwater dolphin kick hydrodynamics in human swimming. Sport Biomech [Internet]. 2009;8(1):60-77. Available from: http://dx.doi.org/10.108o/14763140802629982

54. McCabe C. Effects of 5om and 40om Race Paces on Three-Dimensional Kinematics and Linear Kinetics of Sprint and Distance Front Crawl Swimmers. Edinburgh: University Edinburgh; 2008.

55. Seifert L, Boulesteix L, Chollet D, Vilas-Boas JP. Differences in spatial-temporal parameters and arm-leg coordination in butterfly stroke as a function of race pace, skill and gender. Hum Mov Sci. 2008 Fev;27(1):96-111.

56. Sanders RH. Kinematics, coordination, variability, and biological noise in the prone flutter kick at different levels of a "learn-to-swim" programme. J Sports Sci. 2007 Jan;25(2):213-27.

57. Leblanc H, Seifert L, Baudry L, Chollet D. Arm-leg coordination in flat breaststroke: a comparative study between elite and non-elite swimmers. Int J Sports Med. 2005 Nov;26(9):787-97.

58. Chollet D, Seifert L, Leblanc H, Boulesteix L, Carter M. Evaluation of arm-leg coordination in flat breaststroke. Int J Sports Med. 2004 Out;25(7):486-95.

59. Gautier J, Baly L, Zanone P-G, Watier B. A kinematic study of finswimming at surface. J Sport Sci Med. 2004;3(2):91-5. 
6o. Chollet D, Chalies S, Chatard JC. A new index of coordination for the crawl: description and usefulness. Int J Sports Med. 2000 Jan;21(1):54-9.

61. Richardson AR. The biomechanics of swimming: the shoulder and knee. Clin Sports Med. 1986 Jan;5(1):103-13.

62. Stulberg SD, Shulman K, Stuart S, Culp P. Breaststroker\&\#039;s knee: pathology, etiology, and treatment. Am J Sport Med. 1980;8(3):164-71.

63. Bhalla APS, Griffith BE, Patankar NA. A forced damped oscillation framework for undulatory swimming provides new insights into how propulsion arises in active and passive swimming. PLoS Comput Biol. 2013;9(6):e1003097-e1003097.

64. Toussaint HM, Roos PE, Kolmogorov S. The determination of drag in front crawl swimming. J Biomech. 2004;37(11):1655-63.

65. Sanders RH, Fairweather MM, Alcock A, McCabe CB. An approach to identifying the effect of technique asymmetries on body alignment in swimming exemplified by a case study of a breaststroke swimmer. J Sports Sci Med. 2015 Jun;14(2):304-14.

66. Marinho DA, Rouboa AI, Barbosa TM, Silva AJ. Modelling swimming hydrodynamics to enhance performance. Open Sports Sci J. 2010;3(1):43-6.

67. Cohen RCZ, Cleary PW, Mason B. Improving Understanding of Human Swimming Using Smoothed Particle Hydrodynamics. In: Lim CT, Goh JCH. Proceedings of the Sixth World Congress of Biomechanics. 2010. p. 174-177. (IFMBE; vol. 31). 
